\title{
Effect of SILAR Cycles on the Thickness, Structural, Optical Properties of Cobalt Selenide Thin Films
}

\author{
Egwunyenga, N.J. ${ }^{1}$, Onuabuchi, V.C. ${ }^{2}$, Okoli, N.L. ${ }^{3,{ }^{*}}$ (D) and Nwankwo, I.E. ${ }^{4}$ \\ ${ }^{1}$ Department of Science Laboratory Technology, Delta State polytechnic, Ogwashi - uku, Delta State, Nigeria. \\ 2 Department of Physics, Legacy University, Okija, Anambra State, Nigeria. \\ ${ }^{3}$ Department of Science Education, Enugu State University of Science and Technology, Enugu State, Nigeria. \\ ${ }^{4}$ Department of Science Laboratory Technology, Federal Polytechnic Oko, Anambra State, Nigeria. \\ * Corresponding author email: okolinonsolivinus@gmail.com \\ DOI: https://doi.org/10.34256/irjmt2141
}

Received: 20-03-2021, Revised: 02-06-2021, Accepted: 05-06-2021, Published: 08-06-2021

Abstract: Cobalt Selenide thin films were fabricated using Successive lonic Layer Adsorption and Reaction (SILAR) deposition technique at different SILAR cycles. The precursors for Cobalt and Selenium ions were $\mathrm{CoCl}_{2} \cdot 6 \mathrm{H}_{2} \mathrm{O}$ and $\mathrm{Na}_{2} \mathrm{SeSO}_{3}$ respectively. Optical properties and thickness of the deposited films were studied to determine the effect of number of SILAR cycles on these properties. The optical absorbance of the films was found to decrease as wavelength increases and increases as SILAR cycle increases. Transmittance of the CoSe thin films was found to increase as the wavelength increases but decreases as number of SILAR cycles increased. The extinction coefficient of CoSe thin films decreases as wavelength increases but increases as the SILAR cycles increases. The energy band gap of CoSe thin films deposited decreases from $2.47 \mathrm{eV}$ to $2.20 \mathrm{eV}$ as number of SILAR cycles increases and film thickness increases from $92.96 \mathrm{~nm}$ and $225.63 \mathrm{~nm}$. Structural properties of deposited cobalt selenide thin films showed that they correspond to orthorhombic phase of $\mathrm{CoSe}_{2}$ crystal structure of cobalt selenide thin films with crystallite size ranging from $7.63 \mathrm{~nm}$ to $13.07 \mathrm{~nm}$.

Keywords: Cobalt selenide, Thin Films, SILAR method, Optical Properties, XRD

\section{Introduction}

Binary transition metal chalcogenide systems have recently attracted unlimited consideration due to the fact that they possessed exceptional physical and chemical properties which open windows for various applications. Their ideal optical and electrical properties contributed to them being widely use in solar energy conversion, optoelectronics industries [1, 2]. Recently, huge interests have been channeled to developing these binary transition metal chalcogenides most especially that of selenide families to determine the possibilities of tailoring their optical properties to suite the required values for maximum solar spectrum. According to [3, 4], selenium based compounds have excellent properties that make them good materials for ionic crystal semiconductors, metal superconductors which include ferromagnetism and ferrimagnetism. The semiconducting selenide of interest in this work is Cobalt Selenide (CoSe) thin films.

Cobalt selenide which is one of the transition metal chalcogenide systems belonging to II - VI semiconductor with direct band gap [5]. It has been studied by many researchers for various applications such as dye - sensitized solar cell [6], nano devices [7], magnetic dipoles [8], supercapacitor [9], catalyst for oxygen and hydrogen reduction reaction $[10,11,12]$ and photocatalytic water oxidation [13]. Cobalt selenide thin films have been grown using deposition methods such as electrodeposition [2, 10,14], chemical bath method $[1,5,15,16$,$] . There were no available literatures on$ deposition of CoSe by SILAR method. This singular fact is motivation for this research work.

In this work, cobalt selenide thin films were deposited by SILAR method. Number of SILAR cycles were optimized to determine its effect on the optical and structural properties of the deposited thin film materials.

\section{Experimental details}

The growth of CoSe thin films was carried out by the SILAR method at room temperature. Aqueous solution containing $\left[\mathrm{Co}\left(\mathrm{NH}_{3}\right)_{4}\right]^{2+}$ was prepared by mixing $5 \mathrm{~mL}$ of $36 \% \mathrm{NH} 4 \mathrm{OH}$ with $80 \mathrm{~mL}$ of $0.1 \mathrm{M} \mathrm{CoCl}_{2}$. $6 \mathrm{H}_{2} \mathrm{O}$ until $\mathrm{Co}(\mathrm{OH}) 2$ was precipitated. This solution was used as a cationic precursor and was kept at room 
temperature, while $80 \mathrm{~mL}$ solution of freshly prepared $\mathrm{Na}_{2} \mathrm{SeSO}_{3}$ was used as anionic precursor. $\mathrm{Na}_{2} \mathrm{SeSO}_{3}$ was prepared by refluxing $8 \mathrm{~g}$ of selenium powder with $250 \mathrm{ml}$ of $1 \mathrm{M}$ of sodium sulphite at $90{ }^{\circ} \mathrm{C}$ for 2 hours. The following procedure was adopted to deposit CoSe thin films.

One SILAR growth cycle with cycle time (t_c) equals to 80 seconds shown in figure 1 involved four steps which are Immersion of the cleaned substrate in first reaction bath containing solution of $0.1 \mathrm{M} \mathrm{Co}(\mathrm{OH})_{2}$ for 30s. This process leads to absorption of $\mathrm{Co}^{2+}$ ions on the surface of the substrate.

The substrate was rinsed with double distilled water (DDW) for $10 \mathrm{~s}$ to remove excess $\mathrm{Co}^{2+}$ ions that were loosely bounded to the glass substrate. The substrate was then immersed in freshly prepared $\mathrm{Na}_{2} \mathrm{SeSO}_{3}$ solution for the $30 \mathrm{~s}$. The selenide $\left(\mathrm{Se}^{2-}\right)$ ions reacted with the absorbed $\mathrm{Co} 2+$ ions on the active center of the substrate to form CoSe films. Again, the substrate was rinsed in DDW for $10 \mathrm{~s}$ to remove loosely bounded ions present on the substrate and unreacted $\mathrm{Co} 2+$ and $\mathrm{Se}^{2-}$ ions. The procedure was repeated for 5 cycles to get a uniform film with good thickness.

At the end of a cycle, uniform films were seen on the surface of the microscopic glass substrate. Increase in film thickness was observed as cycles increase. The processes mentioned above were repeated for four other samples with increased number of SILAR cycles of $10,15,20$ and 25 respectively.
The distinctiveness of SILAR method lies in the easy control of thickness and other properties of thin film for various device applications. Deposited CoSe thin films were subjected to optical and structural using StellarNet UV - VIS - NIR spectrometer (Blue - Wave Miniature; Model: UVNb) and $\mathrm{x}$ - ray diffraction machine (Brucker D8 high resolution X-ray diffractometer) Thicknesses of the thin films were obtained using gravimetric techniques.

\section{Results and Discussion}

\subsection{Structural Analysis}

Figure 2 shows diffractograms of cobalt selenide thin deposited at 5 and 25 SILAR cycles. The results showed that $x$ - ray pattern of the deposited thin film corresponding to orthorhombic phase of CoSe with JCPDS file number $(53-0449)$. The $2 \theta$ angles shown in table 1 correspond to miller indices of [110], [101], [111], [211], [031]. A new peak at $62.81^{\circ}$ was observed when SILAR cycles increased to 25 . Increased intensity was observed as SILAR cycles increased from 5 to 25 . This showed improvement in the crystallinity as a result of increase in film thickness as SILAR cycles increased. The improvement in the crystallinity could be of the films as SILAR cycles increased. The crystallite size (D) was calculated using Debye - Scherrer's formula in equation (1) as given by $[17,18\}$ while the dislocation density $(\delta)$, lattice strain $(\varepsilon)$ and inter-planar spacing (d) were evaluated using equation (2), (3) and (4) as given by $[19,20]$.

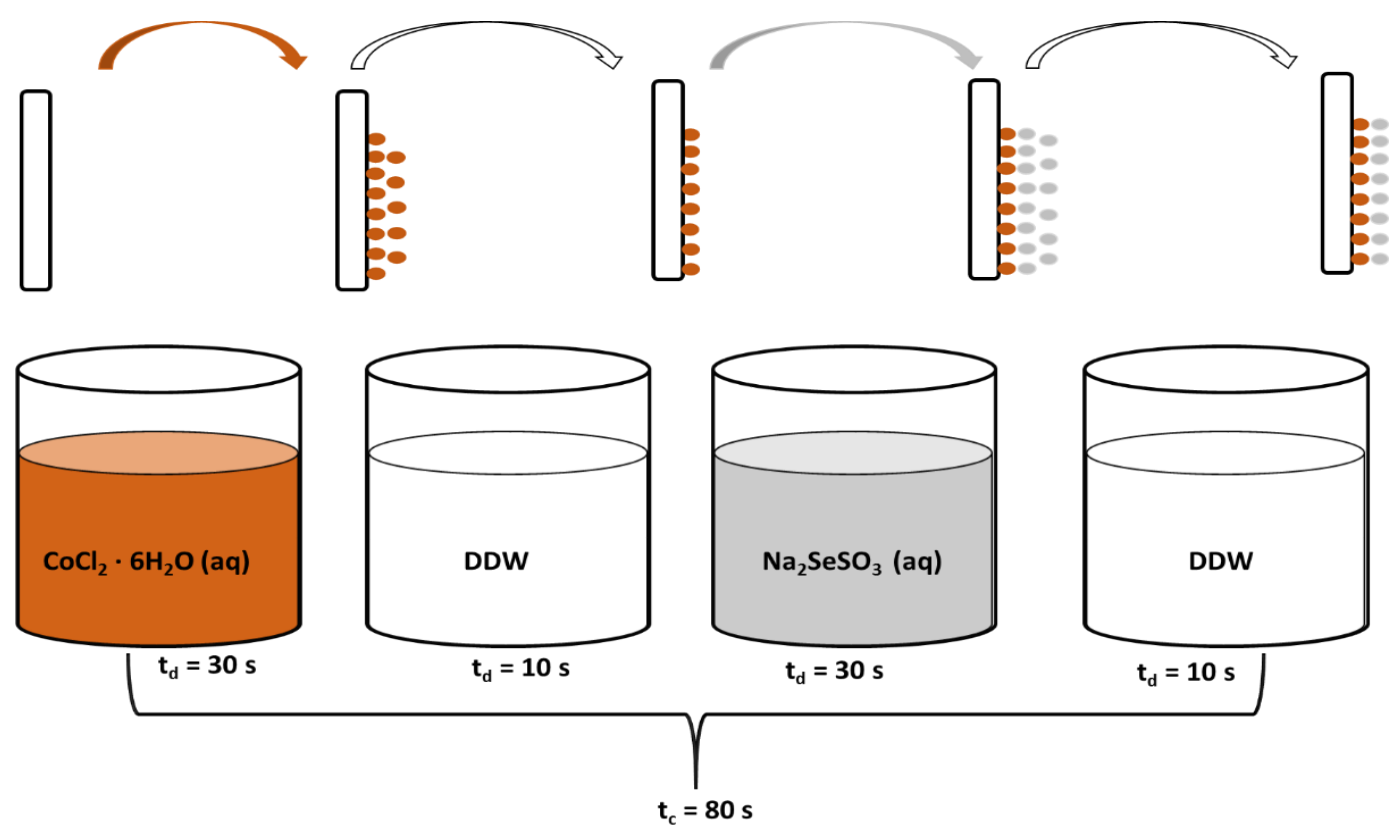

Figure 1 Schematic diagram of SILAR method for the deposition of CoSe thin films $\left(\bullet \rightarrow \mathrm{Co}^{2+}, \bullet \rightarrow \mathrm{Se}^{2-}\right)$ : $t_{d} \rightarrow$ dip time and $t_{c} \rightarrow$ cycle time 


$$
\begin{aligned}
& D=\frac{0.9 \lambda}{\beta \cos \theta} \\
& \delta=\frac{n}{D} \\
& \varepsilon=\frac{\beta}{4 \tan \theta} \\
& d=\frac{\lambda}{2 \sin \theta}
\end{aligned}
$$

Where $\beta$ is the full width half maximum (FWHM) of the observed $2 \theta$ angles, $\theta$ is the diffraction angle, $n$ equals to 1 at minimum dislocation density and $\lambda$ is the wavelength of $\mathrm{Cu}-$ ka radiation $(1.54059 \mathrm{~A})$ used in the $x$ - ray diffraction experiment. The crystallite size of the films is between $7.63 \mathrm{~nm}$ to $13.07 \mathrm{~nm}$. The slight increase observed showed that the crystalline nature of the films increases with increase in SILAR cycles. Decrease in lattice strain and dislocation density confirmed the improvement in the crystal structure of SILAR deposited cobalt selenide as cycle increases. Similar orthorhombic structural phase of $\mathrm{CoSe}_{2}$ were obtained by $[21,22,23]$.

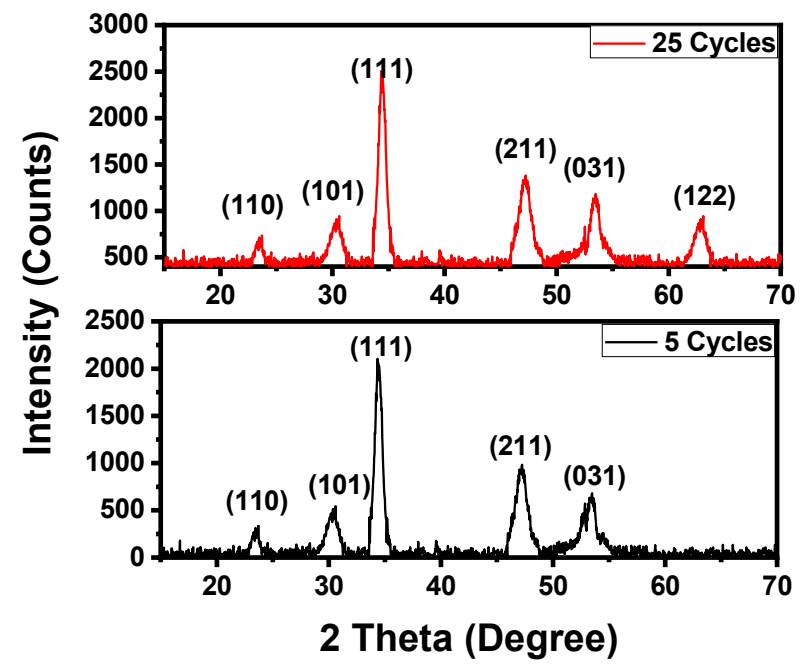

Figure 2 Diffractograms of deposited Cobalt Selenide Thin Films at 5 cycles and 25 cycles.

\subsection{Thickness Measurement}

The thickness of the films shown in figure 3 was obtained using gravimetric method. The area (A) of the substrates covered by the deposited cobalt selenide thin film was measured.by recording dimensions of the substrate covered by the film. The length and width were $4.0 \mathrm{~cm}$ and $2.5 \mathrm{~cm}$ respectively which gave an area of $11.25 \mathrm{~cm}^{2}$. The bulk density $(\rho)$ of CoSe material is 7.65 $\mathrm{g} / \mathrm{cm}^{3}$ while the change in mass $(\Delta m)$ of the substrates was obtained by measuring the mass of the substrates before and after deposition. Values of thickness ( $t$ ) of the deposited thin films were evaluated using equation (5) as given by $[20,24,25]$.

$$
t=\frac{\Delta m}{A \rho}
$$

While growth rates $\left(R_{g}\right)$ were evaluated using equation (6)

$$
R_{g}=\frac{\text { film thickness }(\mathrm{nm})}{\text { number of SILAR cycles }}
$$

Figure 3 shows the plot of thickness and growth rate of the films against number of SILAR cycles. From the figure, the thickness of the films increases as cycle SILAR increases. Thickness of $92.96 \mathrm{~nm}, 116.20 \mathrm{~nm}$, $162.67 \mathrm{~nm}, 209.15 \mathrm{~nm}$ and $255.63 \mathrm{~nm}$ were obtained for $5,10,15,20$ and 25 cycles respectively. Peak thickness $255.63 \mathrm{~nm}$ was obtained for film deposited at 25 SILAR cycles while the least thickness $92.96 \mathrm{~nm}$ was obtained for film deposited at 5 SILAR cycle. This increase is due to formation of ionic layer as SILAR cycle increases. As expected, in one SILAR cycle a single layer

\begin{tabular}{|c|c|c|c|c|c|c|}
\hline Samples & $2 \theta(\circ)$ & $\begin{array}{l}\text { FWHM } \\
\text { (rad) }\end{array}$ & $\begin{array}{c}\text { d - spacing } \\
(\AA)\end{array}$ & $\begin{array}{c}D \\
(\mathbf{n m})\end{array}$ & $\begin{array}{c}\delta \times 10^{15} \\
\left(\text { lines } / \mathrm{m}^{2}\right)\end{array}$ & $\varepsilon \times 10^{-3}$ \\
\hline \multirow[t]{5}{*}{5 cycles } & 23.45 & 0.0165 & 3.79 & 8.94 & 12.52 & 19.93 \\
\hline & 30.33 & 0.0231 & 2.95 & 6.50 & 23.64 & 21.28 \\
\hline & 34.07 & 0.0164 & 2.63 & 9.23 & 11.73 & 13.38 \\
\hline & 47.18 & 0.0221 & 1.92 & 7.15 & 19.55 & 12.65 \\
\hline & 53.43 & 0.0247 & 1.71 & 6.56 & 23.27 & 12.29 \\
\hline \multicolumn{4}{|r|}{ Average } & 7.63 & 18.18 & 14.83 \\
\hline \multirow{6}{*}{$\begin{array}{c}25 \\
\text { cycles }\end{array}$} & 23.45 & 0.0081 & 3.79 & 18.36 & 2.96 & 9.7 \\
\hline & 30.32 & 0.0157 & 2.95 & 9.54 & 11.00 & 14.5 \\
\hline & 34.43 & 0.0076 & 2.60 & 19.95 & 2.51 & 6.13 \\
\hline & 47.18 & 0.0168 & 1.93 & 9.43 & 11.24 & 9.59 \\
\hline & 53.42 & 0.0163 & 1.71 & 9.95 & 10.10 & 8.09 \\
\hline & 62.81 & 0.0152 & 1.48 & 11.16 & 8.03 & 6.23 \\
\hline \multicolumn{4}{|r|}{ Average } & 13.07 & 7.64 & 9.04 \\
\hline
\end{tabular}
of $\mathrm{CoSe}_{2}$ film was deposited. As SILAR cycles increase, more layers of $\mathrm{CoSe}_{2}$ were deposited which leads to increase in film's final thickness This result is similar to increase in the thickness as SILAR cycles increase obtained by $[26,27,28,29]$. 
According to [27], the increase maybe as a result of increase in reaction time available for the growth of thin film. Growth rates $\left(R_{g}\right)$ of deposited $\mathrm{CoSe}_{2}$ were found to decreased as SILAR cycles increases. From 15 SILAR cycles, the growth rate decreased gradually from $10.85 \mathrm{~nm} /$ cycle to $10.23 \mathrm{~nm} /$ cycles. The trend is similar to result obtained by [26].

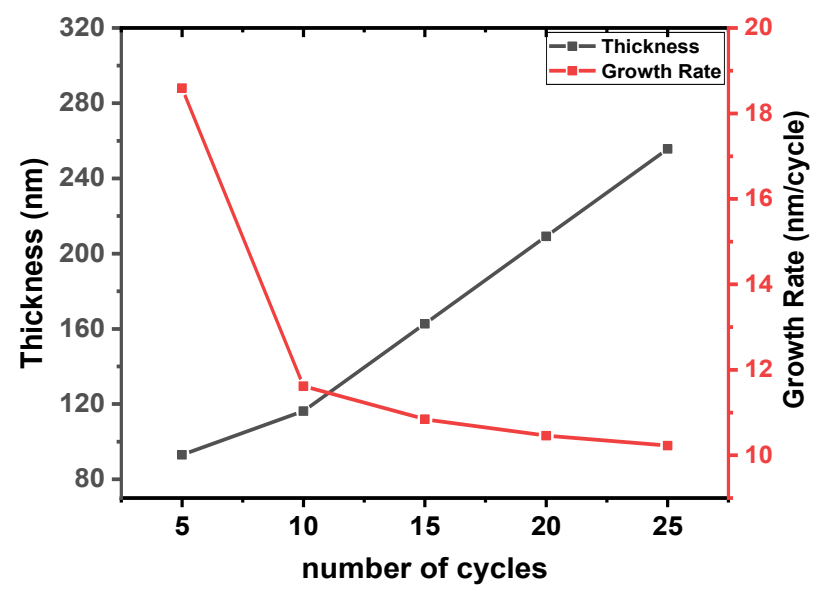

Figure 3 Plot of thickness and growth rate against number of SILAR cycles for Cobalt selenide thin films.

\subsection{Optical Properties}

The optical study was done within the wavelength ranges of $300 \mathrm{~nm}$ to $1100 \mathrm{~nm}$ which represent ultraviolet (UV), visible light (VIS) and near infrared (NIR) portion of the electromagnetic radiation respectively. From the absorbance (A) obtained from spectrophotometer, other properties such as transmittance, extinction coefficient and band gap were calculated. Transmittance ( $T$ ) was determine using equation (7) as given by [30, 31].

$$
T=10^{-A}
$$

Adsorption coefficient values of the deposited thin film were estimated using equation (8) as given by $[32,33]$.

$$
\alpha=\frac{1}{d} \ln \left(\frac{1}{T}\right)
$$

$d$ is the thickness of the deposited thin film and T is the transmittance. Extinction coefficient values of deposited thin film were estimated using equation (9) as given by $[34,35]$.

$$
K=\frac{\alpha \lambda}{4 \pi}
$$

Where $\alpha$ is the optical absorption coefficient and $\lambda$ is the wavelength. Energy band gap values of the films were estimated using equation (10) as given by [36, 37].

$$
\alpha h v=\beta\left(h v-E_{g}\right)^{n}
$$

Where $\beta$ is an independent constant and $\mathrm{n}$ is an index that describes the degree of electron transition by the deposited thin films. In general, $n=\frac{1}{2}$ for direct allowed transition, and $n=\frac{3}{2}$ for indirect forbidden transitions. Skin depth $(\delta)$ that measured the degree of penetration of photons within the surface of the deposited cobalt selenide thin films was estimated using equation (11) as presented by $[38,39]$.

$$
\delta=\frac{1}{\alpha}
$$

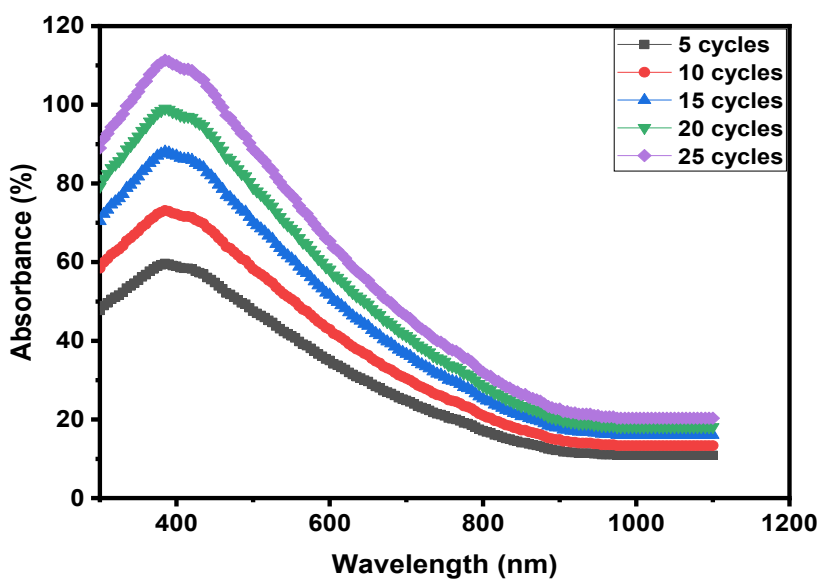

Figure 4 Plot of Absorbance against Wavelength for Cobalt selenide thin films.

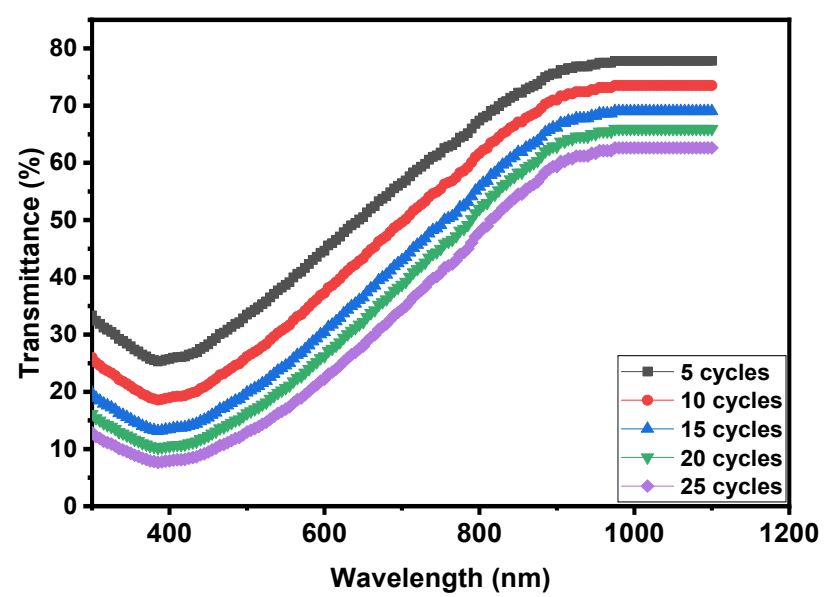

Figure 5 Graph of Transmittance plotted against wavelength for Cobalt selenide thin films.

Figure 4 shows the graph of absorbance of the films plotted against wavelength. From the graph, absorption peak was observed for all the films at 385 $\mathrm{nm}$. This showed that there is no shift in the absorption peaks of CoSe thin films as number of SILAR cycle increases. The absorbance values were found to decreases as wavelength increase. Also, the graph revealed an increase in absorbance as number of SILAR cycles increases. This increase in the absorbance values of CoSe thin film may be as a result of increase in the amount of CoSe atoms formed as the number of cycle increases. Increase in absorption of radiation is due to 
increase in film thickness as SILAR cycles increased from 5 cycles to 25 cycles. The absorbance values of the films ranged between $10.89 \%$ at $1100 \mathrm{~nm}$ to $111.33 \%$ at $300 \mathrm{~nm}$. This result shows that CoSe thin films absorbed UV light more than VIS and NIR.

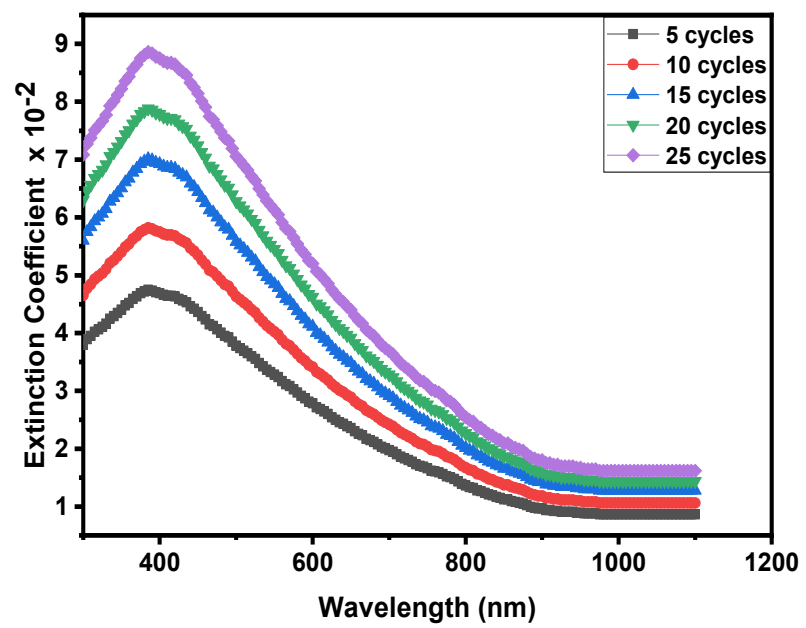

Figure 6 Graph of Extinction coefficient plotted against wavelength for Cobalt selenide thin films.

Figure 5 revealed the graph of transmittance of the films plotted against wavelength. From the graph. The transmittance of CoSe thin films increases as wavelength increases. Also, the graph showed a decrease in transmittance as number of SILAR cycles increases.
The transmittance values of the films decrease from $300 \mathrm{~nm}$ to minimal values at $385 \mathrm{~nm}$ before increasing steadily to peak values at $1100 \mathrm{~nm}$. Transmittance values of the films at $300 \mathrm{~nm}$ are 33.35 $\%, 26.03 \%, 19.17 \%, 16.15 \%$ and $12.88 \%$. Transmittance values of the deposited thin films at 385 nm are $25.32 \%, 18.57 \%, 13.16 \%, 10.22 \%$ and 7.70 $\%$ while transmittance values at $1100 \mathrm{~nm}$ are $77.81 \%$, $73.53 \%, 69.05 \%, 65.94 \%$ and $62.61 \%$ respectively.

Figure 6 shows the graph of extinction coefficient of the films plotted against wavelength. From the graph, extinction coefficient peak was observed for all the films at $385 \mathrm{~nm}$. The extinction coefficient of CoSe thin films decreases as wavelength increase. Also, the graph shows an increase in extinction coefficient as number of SILAR cycles increases. Extinction coefficient values of the films at $300 \mathrm{~nm}$ are $3.79 \times 10^{-2}, 4.65 \times$ $10^{-2}, 5.60 \times 10^{-2}, 6.30 \times 10^{-2}$ and $7.08 \times 10^{-2}$. Peak values at $385 \mathrm{~nm}$ are $4.75 \times 10^{-2}, 5.82 \times 10^{-2}, 7.01 \times$ $10^{-2}, 7.88 \times 10^{-2}$, and $8.86 \times 10^{-2}$ while the values at $1100 \mathrm{~nm}$ are $8.67 \times 10^{-3}, 1.06 \times 10^{-2}, 1.28 \times 10^{-2}$, $1.44 \times 10^{-2}$ and $1.62 \times 10^{-2}$. This result confirmed the absorptive nature of the deposited $\mathrm{CoSe}_{2}$ thin films when exposed to ultraviolet $A$ (UVA) radiations and the films are less absorptive when visible light and near infrared radiations passed through them.
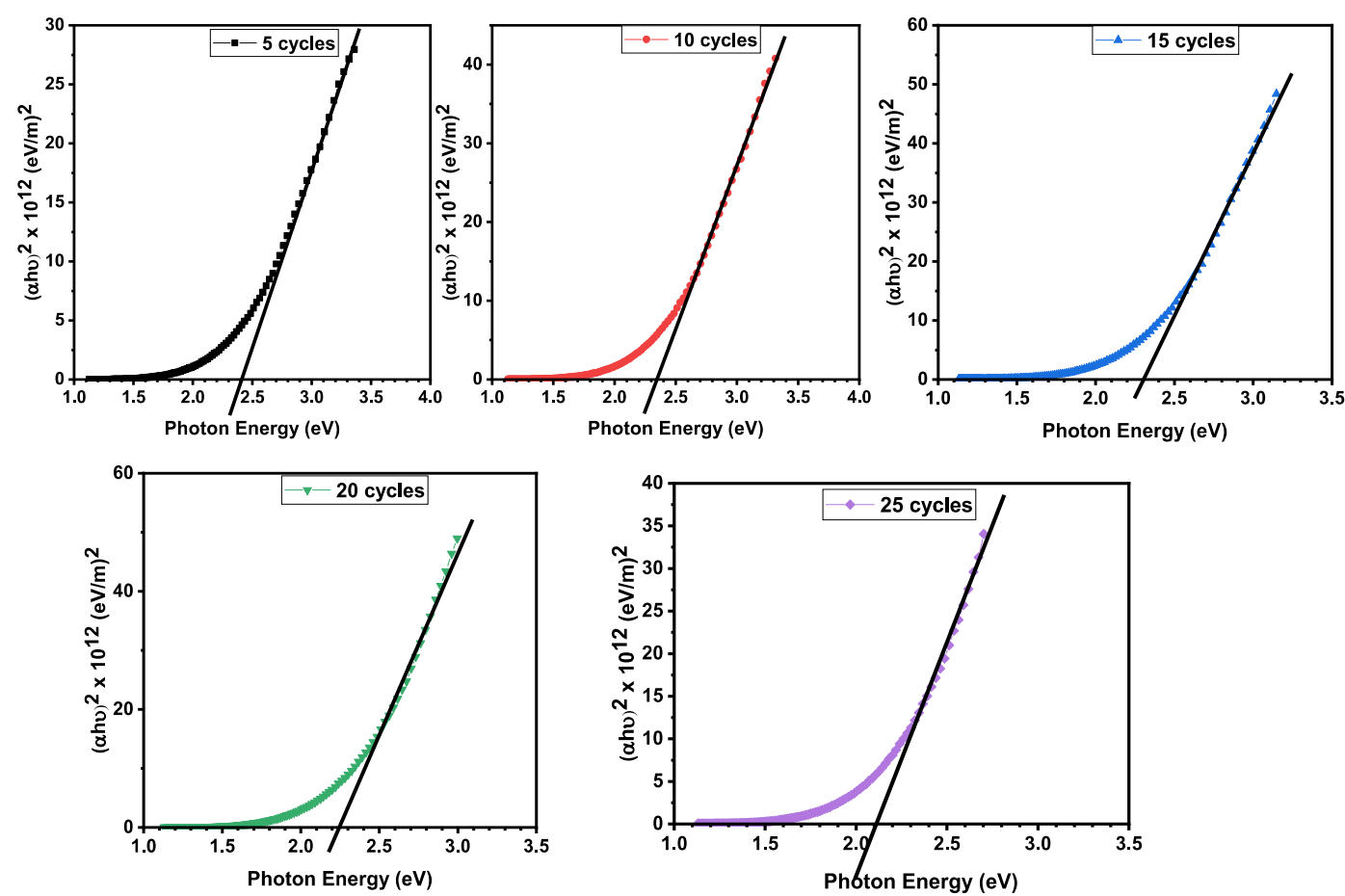

Figure 7 Graph of (ahv) $)^{2}$ plotted against photon energy (eV) for Cobalt selenide thin films. 
Figure 7 shows the plotted graphs of $(\alpha h v)^{2}$ against photon energy $(h v)$ for different number of SILAR cycles carried out. The direct band gap energy was extrapolated at the axis of the photon energy ( $h v)$ where $(\alpha h v)^{2}=0$. CoSe thin film deposited at 5 SILAR cycles has energy band gap of $2.40 \mathrm{eV}$. CoSe thin film deposited at 10 SILAR cycles has energy band gap of $2.35 \mathrm{eV}$. CoSe thin film deposited at 15 SILAR cycles has energy band gap of $2.30 \mathrm{eV}$. CoSe thin film deposited at 20 has band gap of $2.25 \mathrm{eV}$. CoSe thin film deposited at 25 SILAR cycles has band gap of $2.10 \mathrm{eV}$. This show that the energy band gap of CoSe thin films deposited decreases as number of SILAR cycles increases. The values of energy band gap obtained is between the values of $1.5 \mathrm{eV}$ and $3.75 \mathrm{eV}$ obtained [40, 41]. The energy band gap values obtained in this work are in line with values of $2.40 \mathrm{eV}$ to $3.60 \mathrm{eV}$ obtained by [15]. Our energy band gap result shows a reduction in band compared to values of $4.30 \mathrm{eV}$ to $4.25 \mathrm{eV}$ obtained by [5].

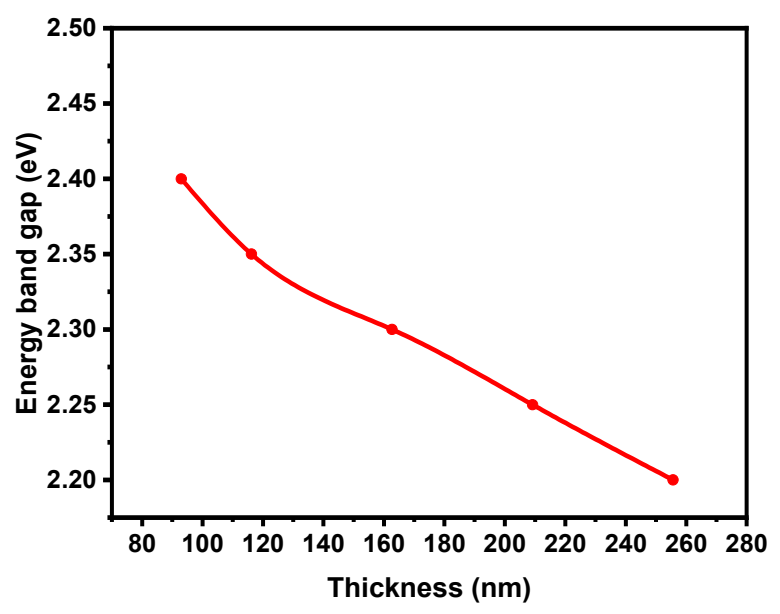

Figure 8 Graph of Energy band gap plotted against thin film thickness for Cobalt selenide thin films.

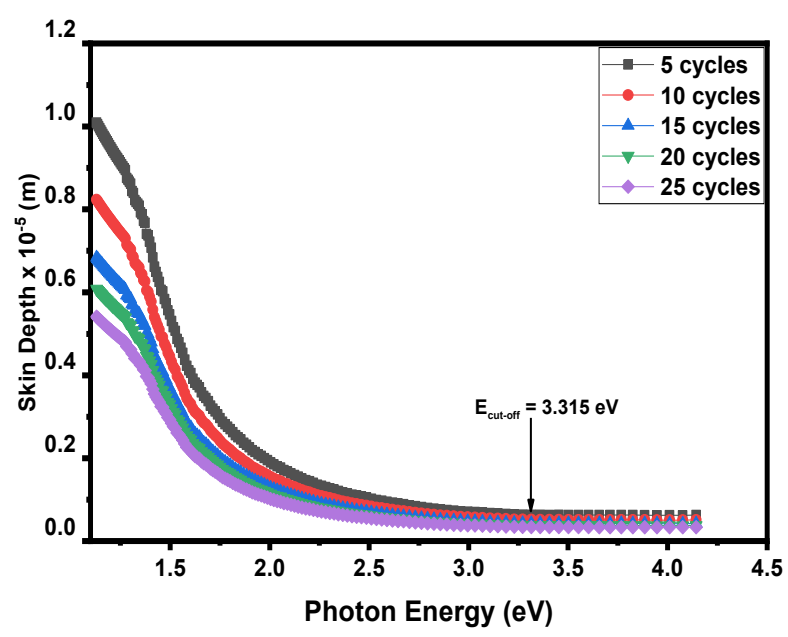

Figure 9 Graph of Skin depth against Photon energy (eV) for Cobalt selenide.
Figure 8 shows the variation of energy band gap with number of SILAR cycles. The energy band gap is found to decrease as film thickness increases. This shows the possibility of tuning the band gap of CoSe thin films at different band parameters. According to [29], the decrease in energy band gap due to increase in SILAR cycles that resulted to increase in film thickness may be as a result of quantum confinement effect, enhancement of the crystallization of the films at lower SILAR cycles and variation in the stoichiometry of the formed thin films. According to [42], energy band gap decreased with increasing SILAR cycles and this is due to increase in the thickness of the films which resulted to increase in the density of the localized state in the energy band gap of CoSe thin film.

Figure 9 showed the plot of skin depth against photon energy for deposited cobalt selenide thin films. Skin depth as an important thin film property defines the absorption of photons within the thin film surface. The skin depth was found to decrease as SILAR cycles increases. Cut - off photon energy $\left(E_{\text {cut-out }}\right)$ of $3.315 \mathrm{eV}$ and corresponding cut - off wavelength $\left(\lambda_{\text {cut-off }}\right)$ of $375.28 \mathrm{~nm}$ was obtained for the SILAR deposited cobalt selenide thin films. Beyond this cut - off wavelength, the absorption effect disappeared and the amplitude goes into extinction as light propagates through a large distance.

\section{Conclusion}

Successive ionic layer adsorption reaction (SILAR) method has been used to successfully deposited cobalt selenide thin films using cobalt (II) chloride hexahydrate, distilled water and sodium selenosulphate obtained by refluxing selenium powder with sodium sulphite. The deposited thin films were subjected to optical and structural characterization using spectrophotometer and $\mathrm{x}$ - ray diffractometer. Absorbance results show that the deposited cobalt selenide thin films have absorption peak at $385 \mathrm{~nm}$. There was no shift in the absorption peak to either longer or shorter wavelength rather the absorbance of the films increases as number of SILAR cycles increase and decreased as wavelength increases with maximum absorbance of 1.11 (111\%) obtained at $385 \mathrm{~nm}$ for films deposited with 25 SILAR cycles and least absorbance of $0.11(10.89 \% \approx 11 \%)$ obtained within the NIR region. Transmittance results of the SILAR deposited cobalt selenide revealed an increase in the transmittance as wavelength increases from $300 \mathrm{~nm}$ to $1100 \mathrm{~nm}$. Also, the transmittance decreases as number of SILAR cycles 
increases. The extinction coefficient of the deposited films decreases as wavelength increases and increases as number of SILAR cycles increases. Peak extinction coefficient values of $4.75 \times 10^{-2}, 5.82 \times 10^{-2}, 7.01 \times$ $10^{-2}, 7.88 \times 10^{-2}$ and $8.86 \times 10^{-2}$ were obtained at 385 $\mathrm{nm}$ for $5,10,15,20$ and 25 SILAR cycles respectively, while least values of $8.67 \times 10^{-3}, 1.06 \times 10^{-2}, 1.28 \times$ $10^{-2}, 1.44 \times 10^{-2}$ and $1.62 \times 10^{-2}$ were obtained at $1100 \mathrm{~nm}$. Energy band gap of the deposited cobalt selenide thin film falls between $2.20 \mathrm{eV}$ and $2.47 \mathrm{eV}$. The energy band gap was found to decrease as number of SILAR cycle increases. This decrease in band gap is as a result of increase in the thickness of the films which is due to increase in the number of SILAR cycles carried out. This shows that cobalt selenide thin films are slightly wide - band gap material. These energy band gap values obtained correspond to great extent with result obtained by other researchers. The thickness of the films is between $92.96 \mathrm{~nm}$ and $225.63 \mathrm{~nm}$.

\section{References}

[1] P.E. Agbo, P.A. Nwofe, R.A. Chikwenze, and D.A. Famuyibo, Effect of pH on Properties of CoSe Thin Films Deposited by Chemical Bath Technique, African Journal of Basic \& Applied Sciences, 8 (3): (2016) $152-156$.

[2] A.M. Kwiecińska, D. Kutyła, K. Kołczyk-Siedlecka, K. Skibińska, P. Żabiński, and R. Kowalik, Electrochemical analysis of co-deposition cobalt and selenium, Journal of Electroanalytical Chemistry, 848, (2019), (113278). [DOI]

[3] P.E. Agbo, and M.N. Nnabuch, Effect of Annealing on the thickness and Bandgap of novel crystalline thin Film, Journal of Ovonic Research, 8 (2012) 127-133.

[4] P.A. Nwofe, K.T.R. Reddy, R.W. Miles, Influence of Deposition Time on the Properties of HighlyOriented SnS Thin Films Prepared Using the Thermal Evaporation Method, Advance Material Research, 602-604 (2013) 1409-1412.

[5] R.A. Chikwenze, J.I. Uba, and J.U. Arikpo, Optical and Electrical Properties of Chemical Bath Deposited Cobalt Selenide Thin Film, Chalcogenide Letters, 14(6), (2017) 211 - 216.

[6] Z. Zhang, S. Pang, H. Xu, Z. Yang, X. Zhang Z. Liu and L. Gu. Electrodeposition of nanostructured cobalt selenide films towards high performance counter electrodes in dye-sensitized solar cells, RSC Advances, 3(37): (2013) 16528 - 16533. [DOI]
[7] H. Luo, D. Wang, J. He, and Y. Lu, Magnetic cobalt nanowire thin films. The Journal of Physical Chemistry B, 109(5): (2005), 1919-1922. [DOI]

[8] J. Gao, B. Zhang, X. Zhang, and B. Xu, MagneticDipolar-Interaction-Induced Self- Assembly Affords Wires of Hollow Nanocrystals of Cobalt Selenide. Angewandte Chemie, 118(8): (2006) 1242-1245. [DOI]

[9] X. Zhang, J. Gong, K. Zhang, W. Zhu, J. Li, and Q. Ding, All-solid-state asymmetric supercapacitor based on porous cobalt selenide thin films, Journal of Alloys and Compounds, 772, (2018) 25 - 32. [DOI]

[10] J. Masud, A.T. Swesi, W.P.R. Liyanage, and M. Nath, Cobalt Selenide Nanostructures: An Efficient Bifunctional Catalyst with High Current Density at Low Coverage, Applied Materials and Interfaces, 8, 27, (2016) 17292-17302. [DOI]

[11] C. Dai, X. Tian, Y. Nie, C. Tian, C. Yang, Z. Zhou, Y. Li, and X. Gao, Successful Synthesis of 3D $\mathrm{CoSe}_{2}$ Hollow Microspheres with High Surface Roughness and Its Excellent Performance in Catalytic Hydrogen Evolution Reaction, Chemical Engineering Journal, 321, (2017) 105 - 112. [DOI]

[12] M. Wang, Z. Dang, M. Prato, U. Petralanda, I. Infante, D.V. Shinde, L. De Trizio, and L. Manna, Ruthenium-Decorated Cobalt Selenide Nanocrystals for Hydrogen Evolution, Applied Nano Materials, 2(9), (2019) 5695 - 5703. [DOI]

[13] G. Zhang, S. Zang, Z. Lan, C. Huang, G. Li, and X. Wang, Cobalt selenide: a versatile cocatalyst for photocatalytic water oxidation with visible light, Journal of Materials Chemistry A, 35, 3, (2015) 17946 - 17950. [DOI]

[14] H. Jee, K. Paeng, N. Myung, and K. Rajeshwar, Compositional Analysis of Electrodeposited Cobalt Selenide Thin Films Using Continuous Flow Electrochemical Quartz Crystal Microgravimetry. Journal of the Electrochemical Society, 165(9), (2018) D370 - D374. [DOI]

[15] R.A. Chikwenze, P.A. Nwofe, P.E. Agbo, and H.U. Igwe, pH Induced Optical Constant Variation of Chemically Deposited CoSe Thin Films. Advances in Natural and Applied Sciences, 9(16) (2015) 36 -40 .

[16] M.L. Gaur, P.P. Hankare, I.S. Mulla, F.M. Dange, and V.M. Bhuse Morphological and optical properties of mixed cadmium cobalt selenide thin film synthesized by chemical bath deposition method for photoelectrochemical applications. 
Journal of Material Science, Materials in Electronics, 27(7), (2016) 7603 - 7608. [DOI]

[17] K. Ravindranah, K.D.V. Prasad, and M.C. Rao, Spectroscopic and Luminescent Properties of $\mathrm{Co}^{2+}$ doped tin oxide thin film by Spray Pyrolysis. Aims Material Science, 3(3): (2016), 796 - 807. [DOI]

[18] C.C. Okorieimoh, U. Chime, A.C. Nkele, A.C. Nwanya, I.G. Madiba, A.K.H. Bashir, S. Botha, P.U. Asogwa, M. Maaza, and F.I. Ezema, Roomtemperature synthesis and optical properties of nanostructured Ba-Doped $\mathrm{ZnO}$ thin films. Superlattices and Microstructures, 130, (2019) 321 - 331. [DOI]

[19] L.N. Ezenwaka, N.S. Umeokwonna, N.L. Okoli, Optical, structural, morphological, and compositional properties of cobalt doped tin oxide (CTO) thin films deposited by modified chemical bath method in alkaline medium, Ceramics International, 46(5), (2020) 6318-6325. [DOI]

[20] C. Awada, G.M. Whyte, P.O. Offor, F. U.Whyte, M.B. Kanoun, S. Goumri-Said, A. Alshoaibi, A.B.C. Ekwealor, M. Maaza, and F.I. Ezema, Synthesis and Studies of Electrodeposited Yttrium Arsenic Selenide Nanofilms for Opto-Electonic Applications. Nanomaterials, 10(8), (2020) 1557. [DOI]

[21] X. Chen, J. Ding, Y. Li, Y. Wu, G. Zhuang, C. Zhang, Z. Zhang, C. Zhu, and P. Yang, Sizecontrollable synthesis of $\mathrm{NiCoSe}_{2}$ microspheres as a counter electrode for dye-sensitized solar cells. RSC Advances, 8(46), (2018) 26047 - 26055. [DOI]

[22] X. Zhao, X. Li, Y. Yan, Y. Xing, S. Lu, L. Zhao, S. Zhou, Z. Peng, and J. Zeng, Electrical and structural engineering of cobalt selenide nanosheets by $\mathrm{Mn}$ modulation for efficient oxygen evolution. Applied Catalysis B: Environmental, 236, (2018) 569-575. [DOI]

[23] A. Ali, and W-C. Oh, Ultrasonic Synthesis of $\mathrm{CoSe}_{2-}$ Graphene- $\mathrm{TiO}_{2}$ Ternary Composites for High Photocatalytic Degradation Performance. Journal of the Korean Ceramic Society, 54(3), (2017) 205210. [DOI]

[24] A.C. Nwanya, D. Obi, R.U. Osuji, R. Bucher, M. Maaza, and F.I. Ezema, (2017). Simple chemical route for nanorod-like cobalt oxide films for electrochemical energy storage applications. Journal of Solid State Electrochemistry, 21(9), (2017) 2567 - 2576. [DOI]

[25] M.R. Belkhedkar, A.U. Ubale, Y.S. Sakhare, N. Zubair, and M. Musaddique, Characterization and antibacterial activity of nanocrystalline $\mathrm{Mn}$ doped
$\mathrm{Fe}_{2} \mathrm{O}_{3}$ thin films grown by successive ionic layer adsorption and reaction method. Journal of the Association of Arab Universities for Basic and Applied Sciences, 21(1), (2016) 38-44. [DOI]

[26] C. Sun, H. Zhao, Y. Shi, Y. Chen, Y. Wu, L. Wang, and B. Guo, Preparation and growth mechanism of solidified $\mathrm{TiO}_{2}$ film on polyimide by SILAR at room temperature. AIP Advances, 9(3), (2019) 035337. [DOI]

[27] H.D. Shelke, A.C. Lokhande, V.S. Raut, A.M. Patil, J.H. Kim, and C.D. Lokhande, Facile synthesis of $\mathrm{Cu}_{2} \mathrm{SnS}_{3}$ thin films grown by SILAR method: effect of film thickness. Journal of Materials Science: Materials in Electronics, 28(11), (2017) 79127921. [DOI]

[28] Y. Akaltun, A. Astam, A. Cerhan, and T. Çayir, Effect of thickness on electrical properties of SILAR deposited SnS thin films. AIP Conference Proceedings, 1722(220001), (2016) 1 - 4. [DOI]

[29] K.B. Chaudhari, N.M. Gosavi, N.G. Deshpande, and S.R. Gosavi, Chemical synthesis and characterization of CdSe thin films deposited by SILAR technique for optoelectronic applications. Journal of Science: Advanced Materials and Devices, 1(4), (2016) 476-481. [DOI]

[30] N.J. Egwunyenga, N.L. Ezenwaka, I.A. Ezenwa, and N.L. Okoli, Effect of annealing temperature on the optical properties of electrodeposited $\mathrm{ZnO} / \mathrm{MgO}$ superlattice, Materials Research Express, 6(10), (2019) 105921(1-9). [DOI]

[31] C. Guo, and M. Kong, Fabrication of Ultralow Stress $\mathrm{TiO}_{2} / \mathrm{SnO}_{2}$ Optical Coating by Palsma Ion Assisted Deposition. Coatings, 10, (2020) 720 (1 13). [DOI]

[32] Q.M. Al-Bataineh, A.M. Alsaad, A.A. Ahmad, and A. Telfah, A novel optical model of the experimental transmission spectra of nanocomposite PVC-PS hybrid thin films doped with silica nanoparticles, Heliyon, 6(6), (2020) e04177. [DOI]

[33] R.Y. Petrus, H.A. Ilchuk, A.I. Kashuba, I.V. Semkiv, E.O. Zmiiovska, and F.M. Honchar, Optical Properties of CdS Thin Films, Journal of Applied Spectrocopy, 87(1) (2020) $35-40$. [DOI]

[34] M.I. El - Radaf, Structural, Optoelectrical, Linear and Non - linear Optical Characterizations of $\mathrm{Cu}_{2} \mathrm{ZnGeSe}_{4}$ Thin Films, Journal of Materials Science: Materials in Electronics, 31, (2020) 3228 - 3237. [DOI]

[35] G.M. Whyte, C. Awada, P.O. Offor, F.U. Whyte, M.B. Kanoun, S. Goumri-Said, A. Alshoaibi, A.B.C. Ekwealor, M. Maaza, and F.I. Ezema, 
Experimental and Theoretical Studies of the Solid State Performance of Electrodeposited $\mathrm{Yb}_{2} \mathrm{O}_{3} / \mathrm{As}_{2} \mathrm{Se}_{3}$ Nanocomposites Thin Films, Journal of Alloys and Compounds, 855(1), (2020), 15734. [DOI]

[36] M.H. Shine, S.A.A. Al - Saati, and F.Z. Razooqi, Preparation of high transmittance $\mathrm{TiO}_{2}$ thin films by sol-gel technique as antireflection coating, Journal of Physics: Conference series, 1032(012018), (2018) 1 - 12. [DOI]

[37] T.A. Hameed, A.R. Wassel, and I.M.I. El-Radaf, Investigating the effect of thickness on the structural, morphological, optical and electrical properties of $\mathrm{AgBiSe}_{2}$ thin films, Journal of Alloys and Compounds, 805 (2019) 1-11. [DOI]

[38] A.M. Alsaad, A.A. Ahmad, I.A. Qattan, Q.M. AlBataineh, and Z. Albataineh, Structural, Optoelectrical, Linear, and Nonlinear Optical Characterizations of Dip-Synthesized Undoped $\mathrm{ZnO}$ and Group III Elements (B, Al, Ga, and In)Doped ZnO Thin Films, Crystals, 10(252) (2020) 1 - 17. [DOI]

[39] I.M. El Radaf, H.Y.S. Al-Zahrani, and A.S. Hassanien, Novel synthesis, structural, linear and nonlinear optical properties of p-type kesterite nanosized $\mathrm{Cu}_{2} \mathrm{MnGeS}_{4}$ thin films, Journal of Materials Science: Materials in Electronics, 31, (2020) 8336-8348. [DOI]

[40] N. Ghobadi and F. Khazaie, Fundamental role of the $\mathrm{pH}$ on the nanoparticle size and optical band gap in cobalt selenide nanostructure films, Optical and Quantum Electronics, 48(165), (2016) $1-8$. [DOI]

[41] N. Ghobadi, F. Hafezi, S. Naderi, F. Amiri, C. Luna, A. Arman, R. Shakoury, S. Tălu, S. Rezaee, M. Habibi, and M. Mardani, Microstructure and Optical Bandgap of Cobalt Selenide Nanofilms. Semiconductors, 53(13) (2019) 1751-1758. [DOI]

[42] T.M. Emeakaroha, B.A. Ezekoye, V.A. Ezekoye, K.O. Ighodalo, Optical and Structural Properties of Silar-Grown Highly oriented Lead Sulphide (PbS) Thin Films, Chalcogenide Letters, 13(3) (2016) 91 $-96$.

\section{Funding}

No funding was received for conducting this study.

\section{Conflict of interest}

The authors have no conflicts of interest to declare that they are relevant to the content of this article.

\section{About the License}

(C) The author(s) 2021. The text of this article is open access and licensed under a Creative Commons Attribution 4.0 International License 